\title{
Effects of aeration strategy on the evolution of dissolved organic matter (DOM) and microbial community structure during sludge bio-drying
}

\author{
Junya Zhang ${ }^{1} \cdot \mathrm{Xing}_{\mathrm{Cai}^{2}} \cdot \mathrm{Lu} \mathrm{Qi}^{3} \cdot$ Chunyan $\mathrm{Shao}^{2} \cdot$ Yang Lin ${ }^{4} \cdot$ Jin Zhang ${ }^{4}$. \\ Yuanli Zhang ${ }^{4} \cdot$ Peihong Shen $^{5} \cdot$ Yuansong Wei $^{1}$
}

Received: 9 February 2015 /Revised: 17 April 2015 / Accepted: 24 April 2015 / Published online: 13 May 2015

(C) Springer-Verlag Berlin Heidelberg 2015

\begin{abstract}
Sludge bio-drying in which sludge is dried by means of the heat generated by the aerobic degradation of its own organic substances has been widely used for sludge treatment. A better understanding of the evolution of dissolved organic matter (DOM) and its degradation drivers during sludge bio-drying could facilitate its control. Aeration is one of the key factors that affect sludge bio-drying performance. In this study, two aeration strategies (pile I - the optimized and pile II - the current) were established to investigate their impacts on the evolution of DOM and the microbial community in a full-scale sludge bio-drying plant. A higher pile temperature in pile I caused pile I to enter the DOM and microbiology stable stage approximately2 days earlier than pile II. The degradation of easily degradable components in the DOM primarily occurred in the thermophilic phase; after that degradation, the DOM components changed a little. Along with the evolution of the DOM, its main degradation driver,
\end{abstract}

Electronic supplementary material The online version of this article (doi:10.1007/s00253-015-6640-z) contains supplementary material, which is available to authorized users.

Yuansong Wei

yswei@rcees.ac.cn

1 Research Center for Eco-Environmental Sciences, Chinese Academy of Sciences, Beijing 100085, China

2 Shenyang Research Academy of Environmental Sciences, Shenyang 110016, China

3 School of Safety and Environmental Engineering, Capital University of Economics and Business, Beijing 100070, China

4 Shenyang Zhenxing Sludge Disposal Co., LTD, Shenyang 110016, Liaoning, China

5 College of Life Science and Technology of Guangxi University, Nanning 530005, Guangxi, China the microbial community, changed considerably. Phyla Firmicutes and Proteobacteria were dominant in the thermophilic stage, and genus Ureibacillus, which was the primary thermophilic bacteria, was closely associated with the degradation of the DOM. In the mesophilic stage, the microbial community changed significantly at first and subsequently stabilized, and the genus Parapedobacter, which belongs to Bacteriodetes, became dominant. This study elucidates the interplay between the DOM and microbial community during sludge bio-drying.

Keywords Microbial community · Sludge bio-drying · Dissolved organic matter

\section{Introduction}

The treatment and disposal of sewage sludge has become a worldwide environmental challenge due to strict legal regulations, land shortages, rising costs, and public concern (Wei et al. 2003). Sludge reduction, including a reduction of volume and quantity as well as stabilization, is the principal goal of sewage sludge treatment. Sludge bio-drying, which is derived from but quite different from composting, which requires a relatively long residence time (30-50 days) (Winkler et al. 2013), is an innovative approach for biomass energy utilization in which sludge is dried by means of the heat generated by the aerobic degradation of its own organic substances (Zhao et al. 2010). Compared to thermal drying in which sludge was dried at relatively high temperatures at the cost of amounts of non-renewable energy resource, it is costeffective and environmentally friendly. It can be considered as an effective volume and quantity reduction process and is used as a pre-treatment method that renders the output more suitable for post-treatment by partial bio-stabilization (Zhao et al. 
2010). Depending on the pre-treatment and different biodrying processes, sludge bio-drying products can be used for incineration, soil amelioration, or landscaping (Yang et al. 2014).

Bio-drying has primarily been studied for municipal solid wastes (MSW) (Velis et al. 2009; Zhang et al. 2009), although a few studies have been reported for sewage sludge bio-drying (Winkler et al. 2013; Zhao et al. 2010). Compared to MSW, there are some problems in sewage sludge bio-drying, including more moisture and lower porosity of biomass matrix, which are disadvantageous to effective aeration and energy recovery (Huiliñir and Villegas 2014). Previous studies had focused on technical parameters and their bio-drying effects, such as initial moisture content and especially aeration strategy. Cai et al. (2013) demonstrated that forced aeration controlled the pile temperature and improved evaporation, making it the key factor that influenced water loss during sewage sludge bio-drying. Sharara et al. (2012) indicated that a high aeration level was superior in terms of both drying energy and time requirements to the other aeration rates that were considered. Additionally, Villegas and Huiliñir (2014) studied initial moisture content (MC) and aeration strategy and proposed kinetics of volatile solid degradation under different initial MC and air-flow rates of sewage sludge bio-drying. However, there is little information about the effects of aeration strategy on the dynamics of organic matter degradation and the microbial mechanisms during sludge bio-drying.

The microbial metabolism for sludge bio-drying is similar to composting. Both consist of mesophilic and thermophilic stages involving numerous microorganisms, but the former aims at MC removal, while the latter focuses on biostabilization and the maturity of the composted materials (Zhang et al. 2009). Overviews of the evolution of the microbial community during sludge composting, including group succession and utilizable substrate for different process stages and temperature ranges, have been reported previously (Nakasaki et al. 2009). Also, evolution of DOM during composting has been widely studied using Fourier transform infrared spectroscopy (FTIR) and three-dimensional excitation-emission matrix (EEM) methods (Said-Pullicino and Gigliotti 2007; Straathof and Comans 2015). However, sludge bio-drying is operated within an MC that is typically lower than optimal composting, and the aeration condition is also managed differently (Velis et al. 2009). Therefore, the behavior of bio-degradation may be atypical compared with composting research results (Adani et al. 2002). In addition, in the past, the composting microbial community was usually studied using traditional methods such as terminal restriction fragment length polymorphism (T-RFLP), PCR denaturing gradient gel electrophoresis (DGGE), clone library, or culturing methods. As a new method for microbial community structure studies, high-throughput sequencing has increased the capacity and rate of the discovery of unknown microorganisms and given a more comprehensive picture of microbial biodiversity (Petrosino et al. 2009) It has been recently used in a few studies on the composting microbial community (Tkachuk et al. 2014), but those studies have focused on the start and the end of composting. Information on the evolution of the microbial community throughout the composting process is still deficient.

Dissolved organic matter (DOM) is the main active organic fraction and is more easily utilized by microorganisms relative to solid-phase organics (Said-Pullicino and Gigliotti 2007). DOM contains soluble breakdown products, bio-originating compounds, and repolymerized macromolecules, which are direct nutritional sources for the microbes. The insoluble organic substrates have to be hydrolyzed to the DOM before biological utilization (Wang et al. 2014). They represent the most active fraction of the organic matter, both biologically and chemically, and thus greatly impact the microbial community and its activity. Therefore, investigating the transformation of DOM is crucial for optimizing sludge bio-drying operations. The chemical composition and structure of DOM have been widely investigated in composting to evaluate the quality of the composting product (Straathof and Comans 2015). However, to our knowledge, there is little information about the evolution of DOM and its degradation driver (the microbial community) during sludge bio-drying. A better understanding of the evolution of DOM and the microbial community structure during sludge bio-drying could facilitate the optimization of the sludge bio-drying operation and improve its performance. Thus, with the aim of enhancing sludge biodrying, two aeration strategies (pile I- the optimized and pile II - the current) for sludge bio-drying were established to investigate their effects on the evolution of the DOM and microbial community in full-scale sludge bio-drying. This study elucidates the interaction between the DOM and microbial community structure during sludge bio-drying.

\section{Materials and methods}

\section{Process description, experimental design, and sampling}

The sludge bio-drying plant located in Shenyang, Liaoning province, in China is designed to treat $1000 \mathrm{t}$ of dewatered sewage sludge at $80 \%$ of MC per day. This plant is the largest sludge bio-drying plant in China. The plant employs a horizontal agitated solid bed process (HASB) with forced aeration and turning. It is designed for reducing the $\mathrm{MC}$ of the dewatered sewage sludge from approximately $80 \%$ to less than $40 \%$. There are 96 tunnels in total, and each tunnel is $90 \mathrm{~m}$ long, $3 \mathrm{~m}$ wide, and $2.5 \mathrm{~m}$ tall. According to the aeration condition, each tunnel was divided into seven parts: one premixed area and six different aeration areas (areas A, B, C, D, E, and F). Their details are shown in Fig. S1. The operational 
period of sludge bio-drying was set at 21 days, during which each pile was turned once a day along with the tunnel at a rate of marching of $4 \mathrm{mday}^{-1}$. The size of each pile was $4 \mathrm{~m}$ long, $3 \mathrm{~m}$ wide, and $2.5 \mathrm{~m}$ tall.

The raw sludge has an average total solid content of $20 \%$ and an organic fraction of $62 \%$ and is mainly from municipal wastewater treatment plants (WWTPs), with a small proportion from industrial WWTPs in Shenyang. Prior to the biodrying process, the raw sludge is mixed with the bio-dried sludge product to control the initial MC at approximately $60 \%$. The pre-dried sludge was previously collected through bio-drying the raw sludge and rice husk. The aeration required for water evaporation and the oxygen supply for the microbial activity were monitored and controlled online.

Two aeration strategies were used for two piles to investigate the effects of aeration on the evolution of DOM and the microbial community; their details are listed in Table 1. One aeration strategy for pile I was designated as the experiment, which was designed according to the functions of aeration in different areas including oxygen supply, heat dissipation, and water evaporation. Another aeration strategy for pile II was designated as the control, which was the aeration process in current use in the plant. In pile I, the aeration in areas A and B was mainly used to supply oxygen for the microbial activity to promote an increase in the pile temperature. In areas C, D, and $\mathrm{E}$, aeration was used to maintain the pile temperature at less than $60{ }^{\circ} \mathrm{C}$ in the thermophilic stage and to allow the sludge bio-drying to progress effectively. In Area F, aeration was mainly used to evaporate water to meet the requirement that the MC should be less than $40 \%$ of the sludge bio-drying product. Details of the design of the aeration strategy for pile I are described in the Supporting Information.

The sampling in piles I and II throughout the sludge biodrying process was carried out on days 1, 3, 5, 7, 11, 14, 17, and 21 , respectively. Because each pile was turned once per day, each pile can be considered to have been homogeneous. To obtain a representative solid sample, the surface area of each pile $(4 \times 3 \mathrm{~m})$ was diagonally divided into four parts, and five sampling points were chosen on the diagonals.
Samples (100-200 g each) were collected at a pile depth of $10-15 \mathrm{~cm}$. The samples were mixed together, and a representative sample $(100 \mathrm{~g})$ was acquired from the mixed samples using the quartering method (Michele et al. 2015). Details of the solid sampling can be found in the Supporting Information (Fig. S2). Meanwhile, the core temperature of each pile was monitored. Each solid sample was divided into two parts; one sample was used for an analysis of physical and chemical parameters, and the other sample was stored at $-20{ }^{\circ} \mathrm{C}$ for further analysis.

\section{Analysis methods for MC, TS, VS, and DOM}

The MC (\%) was measured by drying the solid sample in a drying oven at $105{ }^{\circ} \mathrm{C}$ until a constant weight was achieved; the remaining weight fraction $(1-\mathrm{MC})$ was regarded as total solids (TS (\%)). The volatile solid (VS) content (\%) was analyzed by heating the dried sample at $600{ }^{\circ} \mathrm{C}$ for $6 \mathrm{~h}$ in an electrical muffle furnace. All tests were conducted in duplicate.

The DOM was extracted following the method previously reported (Said-Pullicino and Gigliotti 2007) with a slight modification. Briefly, the freeze-dried solid samples were ground and passed through a 100 mesh, and then, $20 \mathrm{~g}$ of samples was extracted using $200 \mathrm{~mL}$ of distilled water $(1: 10, w / v)$ for $24 \mathrm{~h}$ in a horizontal shaker at $180 \mathrm{rpm}$ at room temperature. The extracts were then centrifuged at 10,000 rpm for $10 \mathrm{~min}$ and filtered through $0.45-\mu \mathrm{m}$ membrane filters. The filtrates that were obtained were used for further analysis. The polysaccharide and protein content in the DOM was measured by the phenol-sulfuric acid method (DuBois et al. 1956), with glucose as the standard, and by a modification of the Bradford method (Peterson 1977), with bovine serum albumin as the standard, respectively.

Prior to the FTIR analysis, the DOM samples were freezedried in a vacuum to evaporate the water, and then, the dried samples were used for the FTIR analysis (FT-IR, Nicolet 8700, USA). Before EEM and size exclusion chromatography (SEC) analyses were performed, the DOM was diluted by the

Table 1 The operation parameters used in this study for pile I and pile II during sludge bio-drying

\begin{tabular}{|c|c|c|c|}
\hline \multicolumn{2}{|l|}{ Parameter } & Pile I & Pile II \\
\hline \multicolumn{2}{|c|}{ Mixing ratio of dewatered sludge and bio-dried sludge product } & $1: 3(v / v)$ & $1: 3(v / v)$ \\
\hline \multicolumn{2}{|c|}{ Pile size (length $\times$ width $\times$ height) } & $4 \times 3 \times 2.5 \mathrm{~m}$ & $4 \times 3 \times 2.5 \mathrm{~m}$ \\
\hline \multirow[t]{2}{*}{ Aeration strategy } & Time control model $\left(\operatorname{min~}^{-1}\right)$ & A 6 ; B 6 ; C 12; D 12; E 14; F 60 & A 4 ; B 8 ; C $15 ;$ D $17 ;$ E $20 ;$ F 30 \\
\hline & $\begin{array}{l}\text { Temperature feedback control model (start aeration } \\
\text { if temperature is above the set temperature) }\end{array}$ & $\begin{array}{l}\text { A } 45^{\circ} \mathrm{C} \text {; B } 55^{\circ} \mathrm{C} \text {; no temperature } \\
\text { control model for other areas }\end{array}$ & $\begin{array}{l}\text { A } 45^{\circ} \mathrm{C} \text {; B } 55^{\circ} \mathrm{C} \text {; no temperature } \\
\text { control model for other areas }\end{array}$ \\
\hline \multicolumn{2}{|l|}{ Turning frequency } & Once a day & Once a day \\
\hline
\end{tabular}

Letters A-F refer to pile sections

${ }^{a}$ If temperature is above the set temperature, temperature feedback control model started, and if not, time control model for A and B would be adopted automatically. 
same amount $(\times 50)$ for all samples to keep the dissolved organic carbon (DOC) below $20 \mathrm{mg} \mathrm{L}^{-1}$. Fluorescence EEM spectroscopy was performed using a PerkinElmer LS50B fluorescence spectrophotometer (PerkinElmer, USA). Excitation and emission were simultaneously scanned at wavelengths from 200 to $400 \mathrm{~nm}$ and from 220 to $550 \mathrm{~nm}$, respectively, at $5-\mathrm{nm}$ intervals. The slit widths were set to $10 \mathrm{~nm}$ for both the excitation and emission monochromators, and the scan speed was set to $1200 \mathrm{~nm} \mathrm{~min}{ }^{-1}$. Molecular weight (MW) distributions were determined by HPSEC, as previously reported (Wang et al. 2010).

\section{High-throughput sequencing}

Each solid sample ( $0.5 \mathrm{~g})$ was collected for DNA extraction in duplicate with the FAST DNA Spin Kit for Soil (MP Biomedicals, USA). The duplicate DNA extracts were then merged together for further PCR amplification. PCR primers $515 \mathrm{~F} /$ 806R targeting the bacteria and archaea 16S V4 region were selected for the microbial community structure analysis (Caporaso et al. 2010). The reverse primer contained a 6-bp error-correcting barcode that was unique to each sample. The barcode was permuted for each sample and allowed the identification of individual samples in a mixture in a single Illumina MiSeq sequencing run. DNA was amplified in triplicate for each sample following the protocol described previously (Caporaso et al. 2010). PCR amplicons were further purified with a DNA purification kit (BioFlux, Japan), and the concentrations were determined using spectrometry (NanoDrop-1000, USA). Amplicons from different samples were then mixed to achieve equal mass concentrations in the final mixture, which were sent out to Novogene Co., Ltd., in Beijing for small-fragment library construction and pair-end sequencing using the Illumina MiSeq sequencing system (Illumina, USA).

\section{Bioinformatics analysis}

Sequencing reads were assigned to each sample according to the unique 6-bp barcode of each sample. The barcode and primers then were removed. Pairs of reads from the original DNA fragments were merged using FLASH (Magoč and Salzberg 2011). The overlapped reads are called "raw reads." The raw reads then were filtered using QIIME quality filters. Default settings for the Illumina processing in QIIME were used. PCR chimeras were filtered out using UCHIME (Edgar et al. 2011). The reads are then "clean reads." The average length of all of the clean reads was $253 \mathrm{bp}$. After the above filtration, the minimum number of selected sequences in the 16 samples was 24,515 . To fairly compare the 16 samples at the same sequencing depth, the sequence number was normalized by extracting the first 24,515 sequences in each sample for all of the following analyses. All of the normalized sequences were uploaded to MG-RAST (http://metagenomics.anl.gov/ linkin.cgi?project=9439).

The taxonomic classification of the sequences of each sample was carried out individually using the Ribosomal Database Project (RDP) Classifier. The sequences to different taxonomy levels were assigned at the bootstrap cutoff of $50 \%$ suggested by the RDP. In addition, the sequences in each set were assigned to phylotype clusters at cutoff levels of 3 and $6 \%$ as described previously (Zhang et al. 2012), and on the basis of these clusters, rarefaction curves, $\mathrm{H}^{\prime}$, E, varH, and Chao1 richness indices were calculated using the relevant RDP pipeline modules.

\section{Data analysis}

The results of MC, VS, and EEM were analyzed through Origin 9.0 (OrginLab, USA). A heat map of the top 10 genera in each sample was built using the R. Circos graph that was produced by the Circos software (http://circos.ca/). According to the relative content of each genus from the classification, a principal component analysis (PCA) was performed using Canoco 5.0 (Microcomputer Power, USA). The data were statistically analyzed and the significance of variance was examined by SPSS 16.0 (Microsoft, USA).

\section{Results}

\section{Sludge bio-drying performance}

The pile temperature was a significant factor that affected water evaporation and organic degradation in the sludge biodrying. This study compared two different aeration strategies that led to two different pile temperature profiles in the thermophilic stage for pile I and pile II, as shown in Fig. 1a. Pile I reached the highest temperature of $78^{\circ} \mathrm{C}$ in area $\mathrm{A}$ (day 1), but the highest temperature of $56^{\circ} \mathrm{C}$ in pile II was reached in area B (day 3). During bio-drying, aeration has three effects (water evaporation, oxygen supply for microbial activity, and heat dissipation), and the time for the aeration of the oxygen supply was shorter than those for heat dissipation and water evaporation in this study (Table 1). In area A (day 1), the aeration rate $\left(6 \mathrm{~min} \mathrm{~h}^{-1}\right)$ for pile I was greater than that $\left(4 \mathrm{~min} \mathrm{~h}^{-1}\right)$ for pile II and resulted in a higher pile temperature in pile I $\left(78{ }^{\circ} \mathrm{C}\right)$, which may indicate that the aeration rate of $4 \mathrm{~min} \mathrm{~h}^{-1}$ (pile II) in area A was insufficient for microbial activity. In area B (days 3 and 5), the aeration rate was increased to $8 \mathrm{~min} \mathrm{~h}^{-1}$ for pile II, the microbial activity increased, and thus, its pile temperature reached a maximum $\left(56{ }^{\circ} \mathrm{C}\right)$. Along with the increasing aeration time, the heat dissipation by aeration was dominant, and thus, the changes in the pile temperature were almost the same for both piles after day 3 (Fig. 1a). 
Fig. 1 Evolution of temperature (a), moisture content (b), and volatile solids (c) during sludge bio-drying

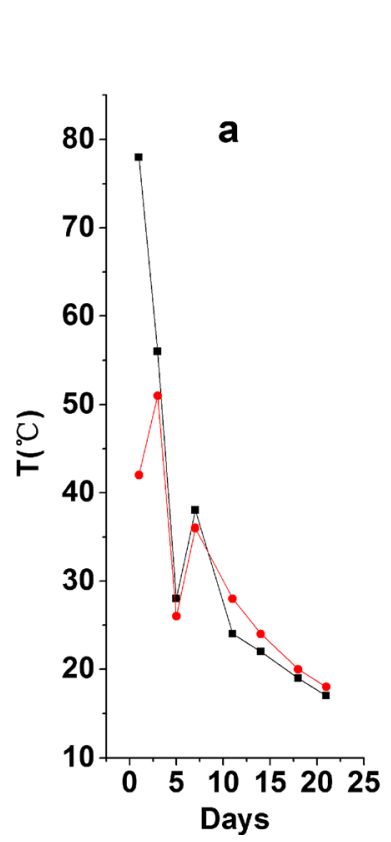

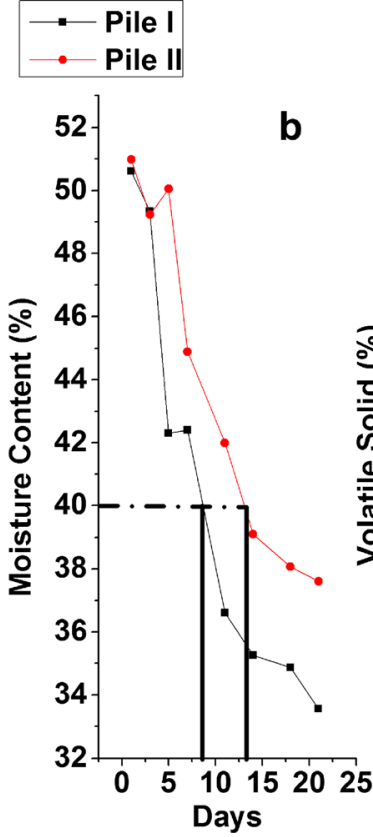

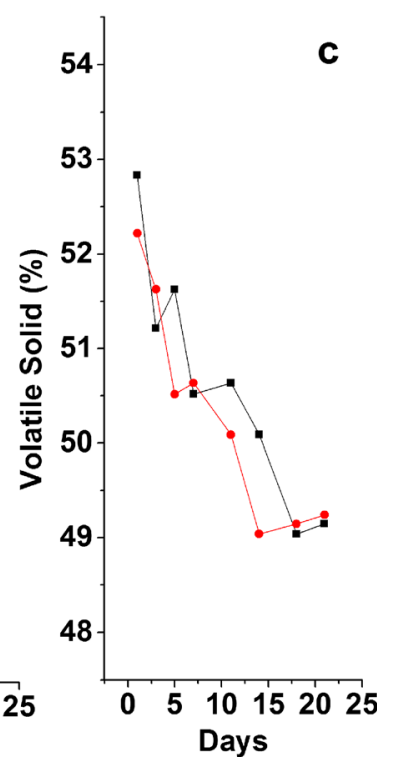

The difference in pile temperature in the first three days resulted in different sludge bio-drying performances (Fig. 1b), and pile I reached the designed bio-drying requirement (MC, $40 \%$ ) much earlier (approximately 2 days) than pile II. It was observed that at the beginning of the sludge biodrying, the reduction of the MC in the sludge was markedly heterogeneous (day 1 to day 5, Fig. 1b), which is in accordance with previous studies (Sugni et al. 2005). The air carried the moisture from the bottom and reached the saturation point as it passed through the matrix. Thus, on reaching the top of the pile, the air could not absorb any more water. As the sludge bio-drying progressed, the dried layer extended to the top gradually after every turning, which drove the reduction of the moisture content. Although the moisture content of both piles at the end of experiments reached the design requirement (40\%), the bio-drying performance of pile I was much better than that of pile II; i.e., not only did pile I reach the designed moisture content faster (about 2 days ahead) than pile II (Fig. 1b) but also the final moisture content of pile I $(33.1 \%)$ was also lower than that of pile II $(37.8 \%)$. These results clearly show that the aeration strategy for pile I was more effective for sludge bio-drying. Jewell et al. (1984) reported maximum moisture removal rates at $46{ }^{\circ} \mathrm{C}$ but maximum organic degradation at $60{ }^{\circ} \mathrm{C}$ during bio-drying of dairy manure. Adani et al. (2002) also confirmed that maximum moisture removal was achieved at $45^{\circ} \mathrm{C}$ and that maximum organic degradation was achieved at $70{ }^{\circ} \mathrm{C}$ during the biodrying of municipal solid waste. In this study, it was also confirmed that the maximum moisture removal rate was achieved between 40 and $50{ }^{\circ} \mathrm{C}$, and the maximum organic degradation rate was achieved at $78^{\circ} \mathrm{C}$ (Fig. 1c). All of these results suggest that at higher pile temperatures, organic degradation dominated, and along with turning, the temperature began to decrease, and moisture removal began to dominate.

\section{Evolution of DOM in sludge bio-drying}

Aeration strategy had an important impact on the evolution of the DOM during sludge bio-drying, and the EEM spectra reflected the evolution of the sludge DOM during bio-drying very well in this study (Fig. 2). According to the EEM spectra analysis, the component of DOM in pile I (after day 5) reached its stable stage earlier (also by approximately 2 days) than pile II (after day 7). The intensity of regions II and IV decreased much on day 5 and day 7 for pile I and pile II, respectively, and after day 3 , the intensity of region II in pile II was much higher than that in pile I. Following Chen et al. (2003), the EEM spectra were divided into five regions depending on the wavelengths of the organics. The comparative evolution of region II in this study indicated that protein-like substances degraded more thoroughly in pile I due to the optimized aeration strategy. In area $\mathrm{A}$, the main function of aeration was to supply oxygen for microbial activity, and the fluorescence intensity of the sludge DOM on day 1 was mainly concentrated in regions II and IV, which suggests that the microbial by-products and aromatic proteins were the major fluorescent DOM. After the thermophilic stage, along with the increasing aeration rate, the fluorescence intensity was greatly reduced in regions II and IV. This change demonstrated the rapid biological transformation of the microbial by-products and proteins in the liquid phase (DOM) during the thermophilic stage of sludge biodrying. The region IV fluorescence intensity of pile I was higher than that of pile II, which suggests higher microbial 

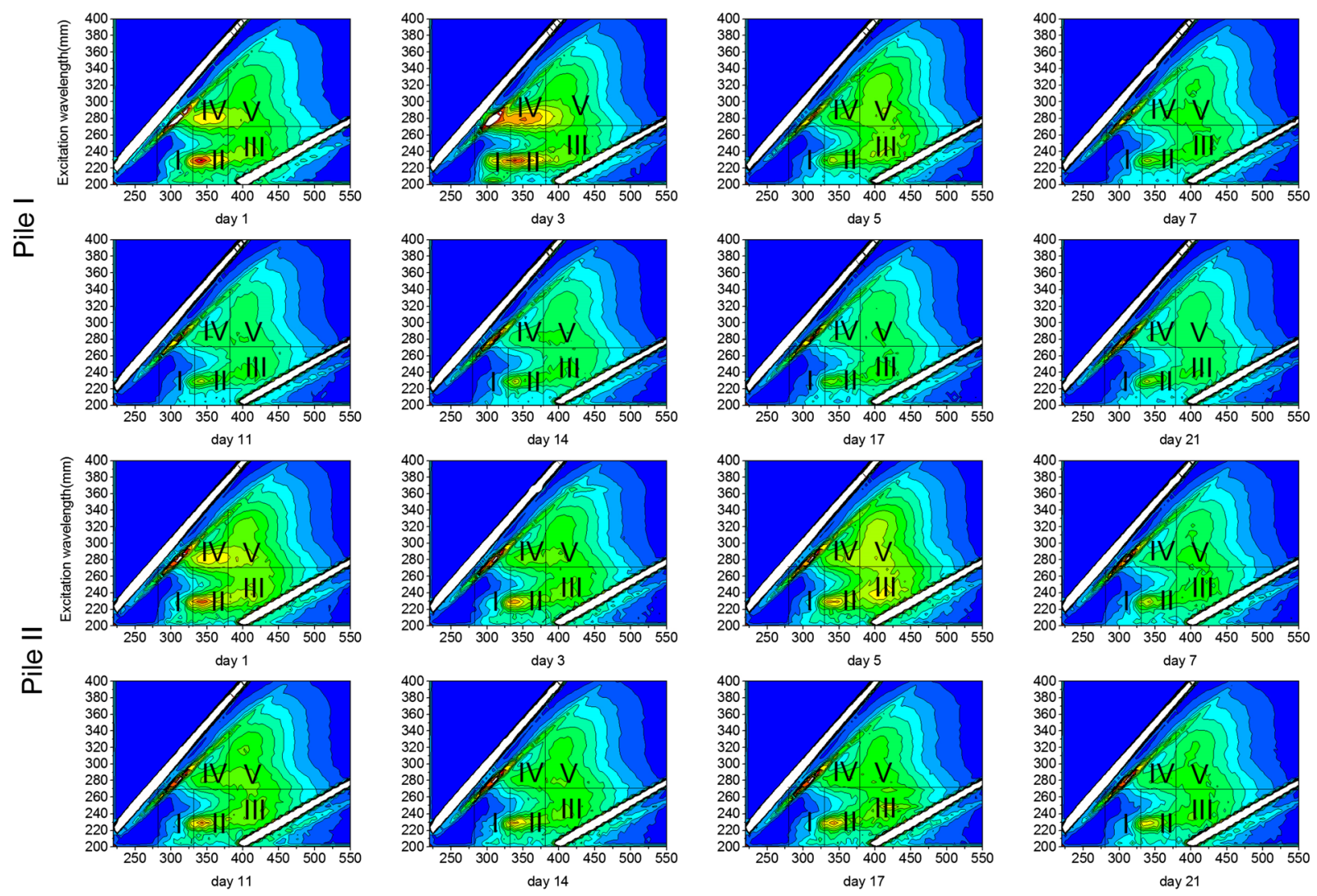

Fig. 2 EEM spectra of dissolved organic matter (DOM) for different samples from piles I and II. Regions I and II, aromatic proteins, III, fulvic acid-like materials, IV, soluble microbial by-product-like materials, and V, humic acid-like materials

activity that resulted in more microbial by-products and a higher temperature. These results were consistent with the evolution of the pile temperature (Fig. 1a). Meanwhile, the fluorescent signal shifted to regions III and V, which indicates that the constituents of the DOM were very well transformed during sludge bio-drying. This is in accordance with previous studies on composting (Zhang et al. 2014). However, along with bio-drying, the fluorescent intensity of regions III and V was gradually reduced and then remained constant, which is relatively different from composting because regions III and V were generally used to represent the maturity of composting (Marhuenda-Egea et al. 2007). Although the aeration time was much higher in the latter area, the components of the DOM changed little (Fig. 2) due to the low moisture content (Fig. 1b). This also demonstrates that sludge bio-drying, unlike sludge composting, is not a stabilization process. A very low moisture content in the sludge would cause early dehydration, which would inhibit the biological process and thus produce physically stable but biologically unstable products (Liang et al. 2003). Sludge bio-drying is designed to remove more $\mathrm{MC}$, and a consequence of this is the loss of DOM. However, this lower moisture content leads to restrained microbial activity, and the remaining DOM is therefore less susceptible to biodegradation. Higher organic content leads to its biologically instability, which can be observed from the EEM spectra (Fig. 2) that show that the humic-like acids were decreasing rather than increasing. In addition, the FTIR analysis (Fig. 3e, f) showed that the absorbance at a wavelength of $1140 \mathrm{~cm}^{-1}$ changed a little and even decreased for pile I, while in composting, it should increase and is used as the maturity mark. This further suggests that sludge bio-drying is quite different from composting.

Two peaks were identified, and the MWs of the resolved peaks were calculated to be $2.3 \mathrm{kDa}$ (peak 1) and $44.7 \mathrm{kDa}$ (peak 2) according to the HPSEC chromatographs (Fig. 3c, d). Peak 1 reached its peak value on day 3 and day 1 for piles I and II, respectively. This suggests that after the higher pile temperature, pile I released more small molecular substances, and thus, concentrations of proteins and polysaccharide in the DOM reached their peaks on day 3 in pile I (Fig. 3a). Likewise from the EEM results, after day 5 for pile I and day 7 for pile II, the concentrations of the proteins and polysaccharides and the MW distributions changed a little. Pile I reached the DOM stable stage more quickly (approximately 2 days earlier), and subsequently, the MC removal was mainly caused by physical aeration rather than microbial activity. To elucidate this notion, we further studied the temporal evolution of the microbial community structures in piles I and II. 


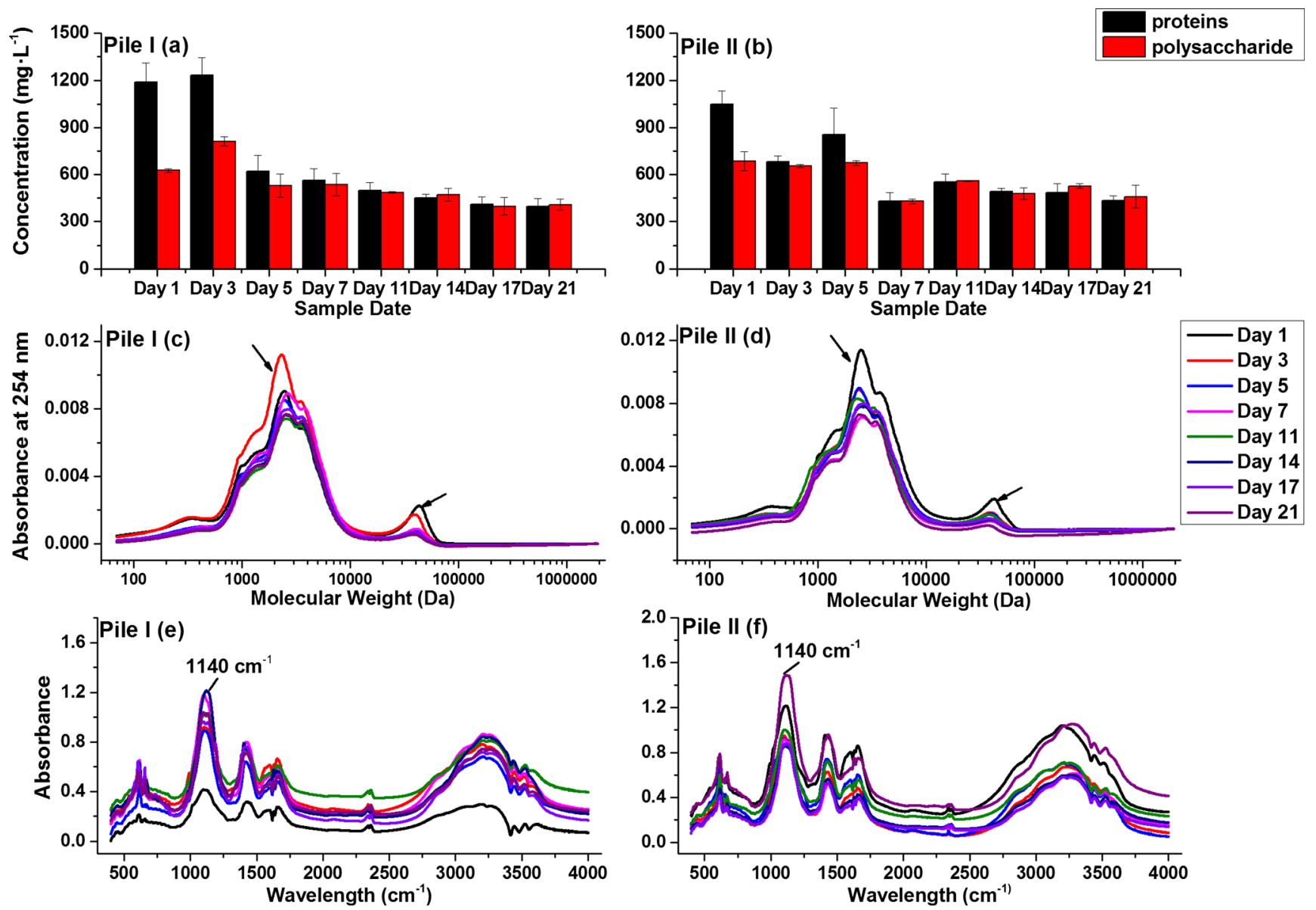

Fig. 3 Temporal evolution of the concentrations of proteins and polysaccharides (a, b), molecular weight (c, d), and Fourier transform infrared spectroscopy (FTIR) analysis for pile I and pile II

\section{Evolution of microbial community structure}

A total of 793,234 high-quality sequences were obtained from 16 solid samples, ranging from 24,515 reads to 88,255 reads; details of the post-run analysis are listed in Tables S1 and S2. For an intercomparison at the same sequencing depth, all of the sample sequences were normalized to 24,515 reads for the downstream analysis.

The numbers of operational taxonomic units (OTUs), Chao $1, \mathrm{H}^{\prime}, \mathrm{E}$, and varH at two cutoff levels (3 and $6 \%$ ) are summarized in Table S3. According to the rarefaction curves (Fig. S3) and the OTU numbers, the diversity of the microbial community in sludge bio-drying was decreasing in both piles. For sludge composting, a previous study has indicated that although the initial pile temperature decreased, the bacterial numbers may have decreased by one to two orders of magnitude, and the taxonomic and metabolic diversity increased (Ryckeboer et al. 2003). This suggests that a low moisture content for sludge bio-drying may not only affect the microbial activity but also affect the microbial diversity. The differences in the aeration strategies did not significantly $(P>0.05)$ affect the evolution of the diversity of the microbial community in either pile I or pile II. The profiles of Chao 1, $\mathrm{H}^{\prime}, \mathrm{E}$, and varH values were very similar to rarefaction curves and OTU numbers.

The 24,515 selected effective bacterial sequences in each sample were assigned to different taxa levels (from genus to phylum) using the RDP Classifier at a $50 \%$ threshold. As shown in Fig. 4, Firmicutes, Proteobacteria, Actinobacteria, and Bactericidetes were the dominant phyla in the bacterial communities of the 16 samples in this study, which is similar to previous studies (Yadav et al. 2014; Ibarbalz et al 2013; Xia et al. 2010). Although the types of the main taxa did not differ much among the samples between the different sludge biodrying stages, the proportions were quite different (Fig. 4). During sludge bio-drying, the abundance of phylum Actinobacteria changed a little. However, phyla Firmicutes and Proteobacteria obviously decreased. They dominated in the thermophilic stage, but as the pile temperature and moisture content decreased, their abundances changed much, from maxima of $39.7 \%$ (Firmicutes in pile I), $27.5 \%$ (Proteobacteria in pile I) $42.1 \%$ (Firmicutes in pile II), and $32.1 \%$ (Proteobacteria in pile II) to minima of $8.0 \%$ (Firmicutes in pile I), $10.3 \%$ (Proteobacteria in pile I), 


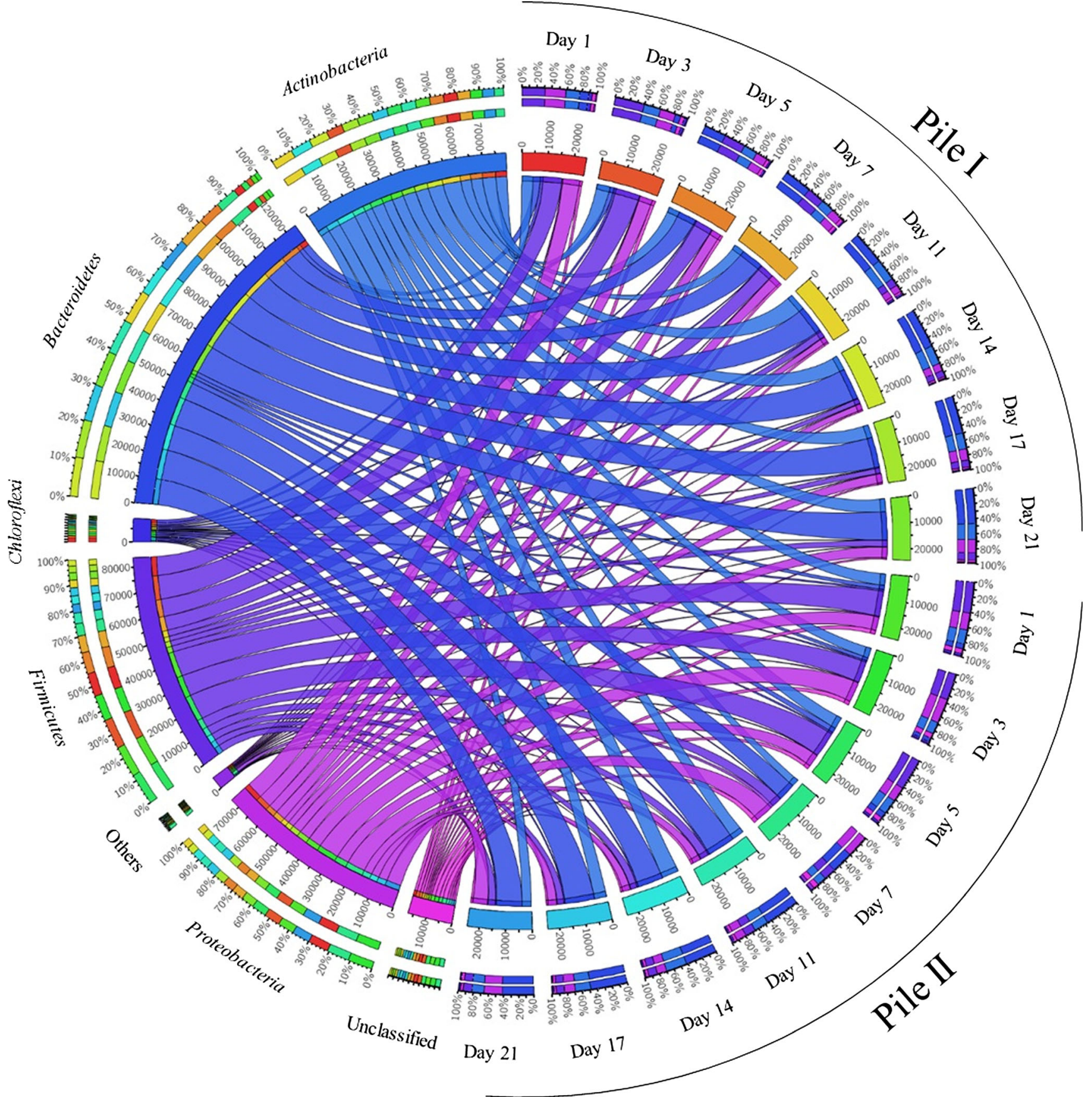

Fig. 4 Evolution of the bacterial community of piles I and II at the phylum level. The width of the bars from each phylum indicate the relative abundance of that phylum in the sample

$10.6 \%$ (Firmicutes in pile II), and $12.7 \%$ (Proteobacteria in pile II). Meanwhile, the abundance of phylum Bacteroidetes increased by up to eight times, from minima of 6.9 and $5.16 \%$ to 52.2 and $48.7 \%$ for piles I and II, respectively.

For a detailed analysis of the microbial community structure, the 10 most abundant genera in each sample were selected (Fig. 5). The genus Actinomadura was abundant (3.0$10.3 \%$ ) in all of the samples, and their abundances in the mesophilic stage were slightly higher. As proposed by Lechevalier and Lechevalier (1970), Actinomadura belongs to family Thermomonosporaceae, phylum Actinomycetes. Members of the genus are aerobic, Gram-positive, non-acidfast actinomycetes that form non-fragmenting branched substrate mycelia and aerial hyphae bearing chains of up to 15 spores. The primary reservoir of Actinomadurae is soil, and a few have been isolated from clinical materials (Yassin et al. 2010). 

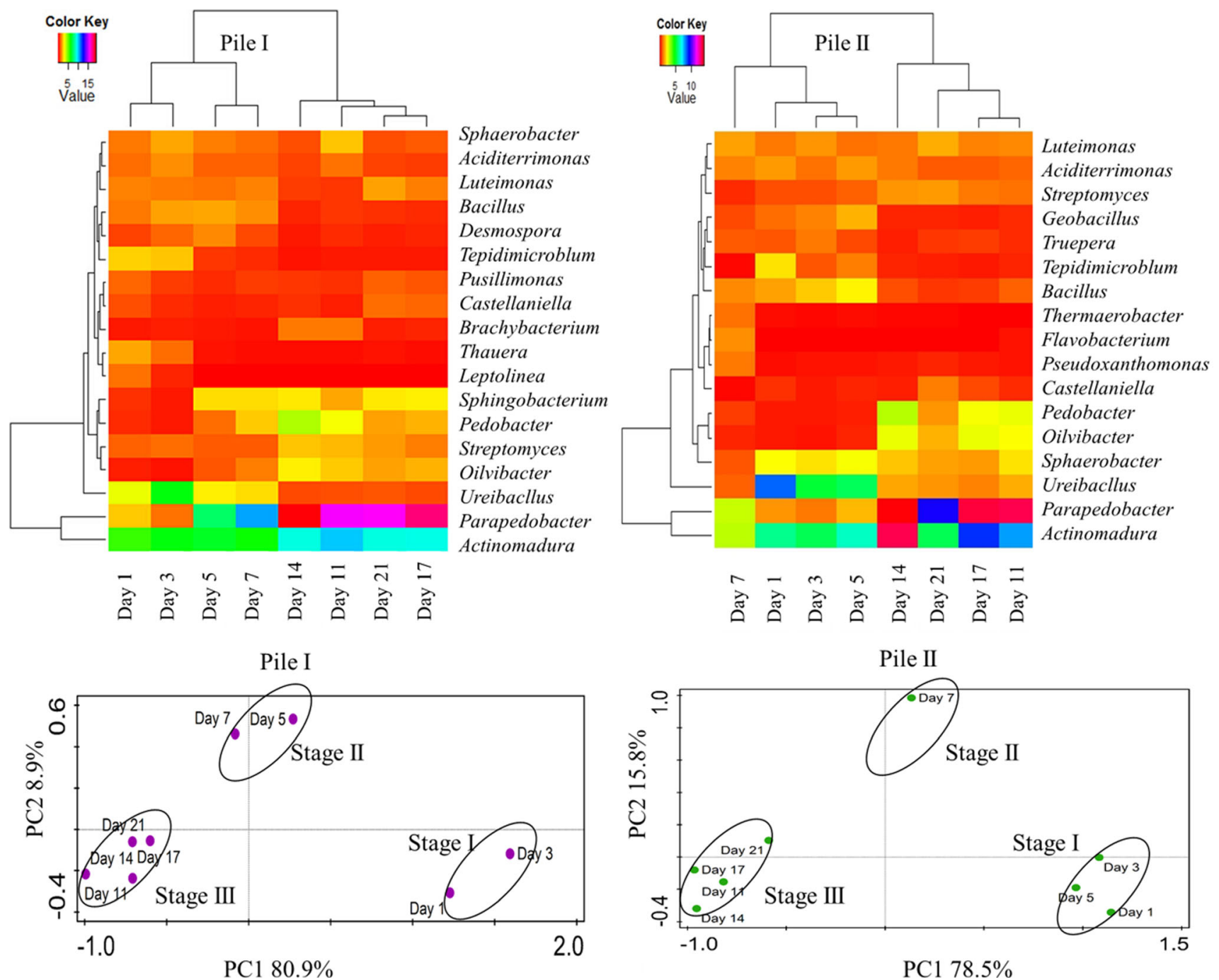

Fig. 5 Heat map of the 10 most prevalent genera in piles I and II (up). The 10 most abundant genera in each sample were selected (a total of 18 and 17 genera for piles I and II, respectively). Principal component analysis (PCA) for the bacterial communities of piles I and II (down)

The dominant genus in the thermophilic stage of sludge bio-drying was Ureibacillus (maximum, $8.6 \%$ ). Nakasaki et al. (2009) compared the microbial community during thermophilic composting of two different types of anaerobic sludge using PCR-DGGE, and Ureibacillus sp. was the observed dominant band during the composting of S-sludge (a high concentration of proteins). Jang et al. (2014) also used PCR-DGGE to study the microbial community of sludge thermophilic aerobic digestion as a sludge pre-treatment for mesophilic anaerobic digestion, and they found that Ureibacillus thermophiles and Bacterium thermus were the major contributors to the increase in soluble organic matter. Ureibacillus sp. is often detected in composting processes and is well known because of its good ability to degrade organic matter. Typical members of Ureibacillus, a genus comprised of thermophilic, aerobic, endospore-forming bacteria, are very active endospore-forming bacteria at temperatures near 50 $60{ }^{\circ} \mathrm{C}$. These microorganisms can produce thermoactive hydrolytic extracellular enzymes (e.g., protease, lipase and cellulase) (Liu et al. 2010) and rapidly break down soluble and easily degradable carbon sources. The relatively high protein-like compound degradation rate (Fig. 2 region II) in the thermophilic stage was consistent with the appearance of Ureibacillus. These results suggest that Ureibacillus may be the dominant potential thermophilic bacteria in sludge biodrying. As the sludge bio-drying progressed, the moisture content and pile temperature decreased, and easily degradable organic matter, such as proteins and microbial by-products in DOM (Fig. 2 regions II and IV), was exhausted, but fulvic and humic-like acids, such as hydrophobic acid (Fig. 2 regions III and V), increased. In the mesophilic stage, Ureibacillus abundance was much reduced to $0.9 \%$ (minimum) from $8.6 \%$ (maximum) for both piles I and II, and other genera, such as the moderately thermophilic and anaerobic genus Tepidimicrobium, were abundant in the thermophilic stage (a maximum of 2.7 and $2.1 \%$ for piles I and II, respectively) but 
were reduced in the mesophilic stage (a minimum of 0.2 and $0.3 \%$ for piles I and II, respectively). The abundances of Bacillus, Geobacillus, and Thauera also showed the same trend (Fig. 5). However, some genera increased in the mesophilic stage of sludge bio-drying. For example, Parapedobacter, belonging to family Sphingobacteriaceae, increased sharply from 1.4 and $1.1 \%$ (the minimum) to 19.1 and $14.2 \%$ (the maximum) for piles I and II, respectively. Members of the genus Parapedobacter, which are Gram-reaction-negative, aerobic, non-spore-forming, rod-shaped, non-motile bacteria and oxidase and catalase positive, have often been isolated in soil and compost (Kim et al. 2010). Some species of the genus have been reported to be able to hydrolyze polycyclic aromatic hydrocarbon and use pyrene as a sole carbon source for growth (Zhao et al. 2013). The fluorescence intensity decrease in regions III and V in the mesophilic stage may be associated with genus Parapedobacter. Other genera, such as Streptomyces, Pedobacter, and Olivibacter, also increased much in the mesophilic stage (Fig. 5).

\section{Discussion}

\section{DOM and its transformation drivers in sludge bio-drying}

Three separate drying stages previously were identified during sludge bio-drying (Roy et al. 2006): (1) increasing drying rate due to acclimatization of microbes, (2) exponential decrease of the drying rate due to insufficient available nutrients for microbe consumption, and (3) constant drying rate due to the fluctuations of the aeration. This indicates that after some point, the sludge bio-drying was less dependent on the microbial activity and became instead only a physical process (air convection) (Velis et al. 2009). In this study, this point may have been day 5 and day 7 for piles I and II, respectively, because after that, $\mathrm{MC}$ removal was still increasing, but the components of the DOM changed a little for either pile (Figs. 2 and 3). In addition, according to the interplay of the DOM and microbial community structure, the sludge biodrying can also be divided into three separate drying stages in this study (Fig. 5): in stage (I) (days 1, 3, and days 1, 3, 5 for pile I and pile II, respectively), the thermophilic bacteria-like genus Ureibacillus dominated, and the easily degradable organics (mainly protein-like substances and microbial metabolic by-products) in the DOM were degraded; in stage (II) (days 5 and 7 and day 7 for pile I and pile II, respectively), the moisture content and pile temperature decreased sharply, the abundance of thermophilic bacteria, such as Ureibacillus, decreased and other mesophilic bacteria, such as Parapedobacter, increased much, but the fulvic and humiclike acids began to decrease; in stage (III), bio-drying entered into a steady physical process promoted by aeration, and the components of the DOM and the microbial community structure changed a little. Although both piles I and II experienced three separate stages, the timing of the stages was different. Pile I entered stage II on day 5, but pile II entered stage II on day 7 (Fig. 5). This suggests that a higher pile temperature due to optimized aeration strategy causes the bio-drying to enter into the microbiology stable stage more quickly (approximately 2 days ahead).

This study investigated the evolution of the degradation of organic matter and its microbial mechanisms in detail during sludge bio-drying. The study not only provides a practical basis but also presents chemical and microbial mechanisms to optimize the operation of sludge bio-drying and improve its performance. The following conclusions are drawn:

1. According to the EEM, SEC, FTIR, and concentrations of proteins and polysaccharide analysis, the degradation of the DOM mainly occurred in the thermophilic stage; after that, the DOM component was a little changed.

2. High-throughput sequencing results demonstrated that during sludge bio-drying, the main microbes that contributed to the degradation of DOM in the thermophilic stage belonged to genus Ureibacillus, and the main mesophilic microbes after the thermophilic stage belonged to genus Parapedobacter. As the sludge bio-drying progressed, the diversity of the microbial community decreased gradually.

3. The optimized aeration strategy caused the DOM and microbial community to enter into a stable stage much faster (approximately 2 days earlier). Not only did pile I (optimized) reach the designed moisture content (40\%) more quickly than pile II but also the final moisture content of pile I (33.1\%) was also lower than that of pile II $(37.8 \%)$.

Acknowledgments This work is supported by the National Water Pollution Control and Management Technology Major Project of China (2012ZX07202-005) and the National Natural Science Foundation of China (21377151).

Conflict of interest The authors declare no conflict of interest.

\section{References}

Adani F, Baido D, Calcaterra E, Genevini P (2002) The influence of biomass temperature on biostabilization-biodrying of municipal solid waste. Bioresour Technol 83:173-179

Cai L, Chen T, Gao D, Zheng G, Liu H (2013) Influence of forced air volume on water evaporation during sewage sludge bio-drying. Water Res 47:4767-4773

Caporaso JG, Lauber CL, Walters WA, Berg-lyons D, Lozupone CA, Turnbaugh PJ, Fierer N, Knight R (2010) Global patterns of 16S rRNA diversity at a depth of millions of sequences per sample. Proc Natl Acad Sci U S A 108:1516-1522 
Chen W, Westerhoff P, Leenheer JA, Booksh K (2003) Fluorescence excitation-emission matrix regional integration to quantify spectra for dissolved organic matter. Environ Sci Technol 37:5701-5710

DuBois M, Gilles KA, Hamilton JK, Rebers PA, Smith F (1956) Colorimetric method for determination of sugars and related substances. Anal Chem 28:350-356

Edgar RC, Haas BJ, Clemente JC, Quince C, Knight R (2011) UCHIME improves sensitivity and speed of chimera detection. Bioinformatics 27:2194-2200

Huiliñir C, Villegas M (2014) Biodrying of pulp and paper secondary sludge: kinetics of volatile solids biodegradation. Bioresour Technol 157:206-213

Ibarbalz FM, Figuerola ELM, Erijman L (2013) Industrial activated sludge exhibit unique bacterial community composition at high taxonomic ranks. Water Res 47:3854-3864

Jang HM, Cho HU, Park SK, Ha JH, Park JM (2014) Influence of thermophilic aerobic digestion as a sludge pre-treatment and solids retention time of mesophilic anaerobic digestion on the methane production, sludge digestion and microbial communities in a sequential digestion process. Water Res 48:1-14

Jewell WJ, Dondero NC, van Soest PJ, Cummings RT, Vegara WW, Linkenheil R (1984) High temperature stabilization and moisture removal from animal wastes for by-product recovery. Final report for the Cooperative State Research Service, US Department of Agriculture, USA, p 169

Kim S-J, Weon H-Y, Kim Y-S, Yoo S-H, Kim B-Y, Anandham R, Kwon S-W (2010) Parapedobacter luteus sp. nov. and Parapedobacter composti sp. nov., isolated from cotton waste compost. Int J Syst Evol Microbiol 60:1849-1853

Lechevalier MP, Lechevalier H (1970) Chemical composition as a criterion in the classification of aerobic actinomycetes. Int J Syst Bacteriol 20:435-443

Liang C, Das KC, McClendon RW (2003) The influence of temperature and moisture contents regimes on the aerobic microbial activity of a biosolids composting blend. Bioresour Technol 86:131-137

Liu S, Song F, Zhu N, Yuan H, Cheng J (2010) Chemical and microbial changes during autothermal thermophilic aerobic digestion (ATAD) of sewage sludge. Bioresour Technol 101:9438-9444

Magoč T, Salzberg SL (2011) FLASH: fast length adjustment of short reads to improve genome assemblies. Bioinformatics 27:2957-2963

Marhuenda-Egea FC, Martínez-Sabater E, Jordá J, Moral R, Bustamante MA, Paredes C, Pérez-Murcia MD (2007) Dissolved organic matter fractions formed during composting of winery and distillery residues: evaluation of the process by fluorescence excitationemission matrix. Chemosphere 68:301-309

Michele P, Giuliana D, Carlo M, Sergio S, Fabrizio A (2015) Optimization of solid state anaerobic digestion of the OFMSW by digestate recirculation: a new approach. Waste Manag 35:111-118

Nakasaki K, Tran LTH, Idemoto Y, Abe M, Rollon AP (2009) Comparison of organic matter degradation and microbial community during thermophilic composting of two different types of anaerobic sludge. Bioresour Technol 100:676-682

Peterson GL (1977) A simplification of the protein assay method of Lowry et al. which is more generally applicable. Anal Biochem 83:346-356

Petrosino JF, Highlander S, Luna RA, Gibbs RA, Versalovic J (2009) Metagenomic pyrosequencing and microbial identification. Clin Chem 55:856-866

Roy G, Jasmin S, Stuart P (2006) Technical modelling of a batch biodrying reactor for pulp and paper mill sludge. CHISA 2006. 17th Int Congr Chem Process Eng 24:20

Ryckeboer J, Mergaert J, Vaes K, Klammer S (2003) A survey of bacteria and fungi occurring during composting and self-heating processes. Ann Microbiol 53:349-410
Said-Pullicino D, Gigliotti G (2007) Oxidative biodegradation of dissolved organic matter during composting. Chemosphere 68:1030-1040

Sharara M, Sadaka S, Costello T, VanDevender K (2012) Influence of aeration rate on the physio-chemical characteristics of biodried dairy manure - wheat straw mixture. Appl Eng Agric 28:407-415

Straathof AL, Comans RNJ (2015) Input materials and processing conditions control compost dissolved organic carbon quality. Bioresour Technol 179:619-623

Sugni, M, Calcaterra, E, Adani, F (2005) Biostabilization-biodrying of municipal solid waste by inverting air-flow. Bioresour Technol 96: $1331-1337$

Tkachuk VL, Krause DO, Knox NC, Hamm AC, Zvomuya F, Ominski $\mathrm{KH}$, McAllister TA (2014) Targeted 16S rRNA high-throughput sequencing to characterize microbial communities during composting of livestock mortalities. J Appl Microbiol 116:1181-1194

Velis CA, Longhurst PJ, Drew GH, Smith R, Pollard SJT (2009) Biodrying for mechanical-biological treatment of wastes: a review of process science and engineering. Bioresour Technol 100:27472761

Villegas M, Huiliñir C (2014) Biodrying of sewage sludge: kinetics of volatile solids degradation under different initial moisture contents and air-flow rates. Bioresour Technol 174:33-41

Wang D, Xing L, Xie J, Chow CWK, Xu Z, Zhao Y, Drikas M (2010) Application of advanced characterization techniques to assess DOM treatability of micro-polluted and un-polluted drinking source waters in China. Chemosphere 81:39-45

Wang K, Li X, He C, Chen C-L, Bai J, Ren N, Wang J-Y (2014) Transformation of dissolved organic matters in swine, cow and chicken manures during composting. Bioresour Technol 168:222-228

Wei Y, Van Houten RT, Borger AR, Eikelboom DH, Fan Y (2003) Minimization of excess sludge production for biological wastewater treatment. Water Res 37:4453-4467

Winkler M-KH, Bennenbroek MH, Horstink FH, van Loosdrecht MCM, van de Pol G-J (2013) The biodrying concept: an innovative technology creating energy from sewage sludge. Bioresour Technol 147: 124-129

Xia S, Duan L, Song Y, Li J, Piceno YM, Andersen GL, Alvarez-Cohen L, Moreno-Andrade I, Huang C-L, Hermanowicz SW (2010) Bacterial community structure in geographically distributed biological wastewater treatment reactors. Environ Sci Technol 44:7391-7396

Yadav TC, Khardenavis AA, Kapley A (2014) Shifts in microbial community in response to dissolved oxygen levels in activated sludge. Bioresour Technol 165:257-264

Yang B, Zhang L, Jahng D (2014) Importance of initial moisture content and bulking agent for biodrying sewage sludge. Dry Technol 32: $135-144$

Yassin AF, Spröer C, Siering C, Klenk H-P (2010) Actinomadura sputi sp. nov., isolated from the sputum of a patient with pulmonary infection. Int J Syst Evol Microbiol 60:149-153

Zhang D-Q, He P-J, Yu L-Z, Shao L-M (2009) Effect of inoculation time on the bio-drying performance of combined hydrolytic-aerobic process. Bioresour Technol 100:1087-1093

Zhang T, Shao M-F, Ye L (2012) 454 pyrosequencing reveals bacterial diversity of activated sludge from 14 sewage treatment plants. ISME J 6:1137-1147

Zhang J, Lü F, Shao L, He P (2014) The use of biochar-amended composting to improve the humification and degradation of sewage sludge. Bioresour Technol 1:1-7

Zhao L, Gu W-M, He P-J, Shao L-M (2010) Effect of air-flow rate and turning frequency on bio-drying of dewatered sludge. Water Res 44 : 6144-6152

Zhao J-K, Li X-M, Zhang M-J, Jin J, Jiang C-Y, Liu S-J (2013) Parapedobacter pyrenivorans sp. nov., isolated from a pyrenedegrading microbial enrichment, and emended description of the genus Parapedobacter. Int J Syst Evol Microbiol 63:3994-3999 